\title{
Selected Ionotropic Receptors and Voltage-Gated Ion Channels: More Functional Competence for Human Induced Pluripotent Stem Cell (iPSC)-Derived Nociceptors
}

\author{
Clemens L. Schoepf ${ }^{+}{ }^{+}$, , Maximilian Zeidler $^{\dagger}$, Lisa Spiecker, Georg Kern, Judith Lechner, \\ Kai K. Kummer ${ }^{\mathbb{D}}$ and Michaela Kress *(D) \\ Institute of Physiology, Medical University of Innsbruck, 6020 Innsbruck, Austria; \\ clemens.schoepf@i-med.ac.at (C.L.S.); maximilian.zeidler@student.i-med.ac.at (M.Z.); \\ lisa.spiecker@uni-oldenburg.de (L.S.); georg.kern@i-med.ac.at (G.K.); judith.lechner@i-med.ac.at (J.L.); \\ kai.kummer@i-med.ac.at (K.K.K.) \\ * Correspondence: michaela.kress@i-med.ac.at; Tel.: +43-512-9003-70800; Fax: +43-512-9003-73800 \\ + These authors contributed equally to this work.
}

Received: 30 April 2020; Accepted: 30 May 2020; Published: 3 June 2020

\begin{abstract}
Preclinical research using different rodent model systems has largely contributed to the scientific progress in the pain field, however, it suffers from interspecies differences, limited access to human models, and ethical concerns. Human induced pluripotent stem cells (iPSCs) offer major advantages over animal models, i.e., they retain the genome of the donor (patient), and thus allow donor-specific and cell-type specific research. Consequently, human iPSC-derived nociceptors (iDNs) offer intriguingly new possibilities for patient-specific, animal-free research. In the present study, we characterized iDNs based on the expression of well described nociceptive markers and ion channels, and we conducted a side-by-side comparison of iDNs with mouse sensory neurons. Specifically, immunofluorescence (IF) analyses with selected markers including early somatosensory transcription factors (BRN3A/ISL1/RUNX1), the low-affinity nerve growth factor receptor (p75), hyperpolarization-activated cyclic nucleotide-gated channels (HCN), as well as high voltage-gated calcium channels (VGCC) of the $\mathrm{Ca}_{\mathrm{V}} 2$ type, calcium permeable TRPV1 channels, and ionotropic $\mathrm{GABA}_{\mathrm{A}}$ receptors, were used to address the characteristics of the iDN phenotype. We further combined IF analyses with microfluorimetric $\mathrm{Ca}^{2+}$ measurements to address the functionality of these ion channels in iDNs. Thus, we provide a detailed morphological and functional characterization of iDNs, thereby, underpinning their enormous potential as an animal-free alternative for human specific research in the pain field for unveiling pathophysiological mechanisms and for unbiased, disease-specific personalized drug development.
\end{abstract}

Keywords: TRPV1; HCN channel; voltage-gated calcium channel; KCC3; synaptic varicosity; p75; sensory neuron; pain; analgesic

\section{Introduction}

Over the past decades, animal experiments have been the gold standard for pain research and, without question, have tremendously contributed to the current knowledge in the field. However, besides ethical concerns, the results achieved in rodent models are confounded by interspecies differences when translating findings to humans. Translational approaches using human tissues have become increasingly important, however, are limited by ethical concerns and the accessibility of human life tissue. The dorsal root ganglia (DRG) and the trigeminal ganglia, which contain the majority of 
primary sensory neurons, are unattainable in a living human being and have even proven complicated to be obtained post mortem [1]. The caveat of species-to-species differences has become evident by recent studies that have compared specific nociceptive markers between human post-mortem and mouse neurons obtained from the DRG; the human proteome includes 286 proteins that are not even expressed in rodent DRG [2]. Functional neuron-like cells differentiated from human induced pluripotent stem cells (iPSCs) provide an elegant way to circumvent interspecies differences, and a protocol to robustly generate human iPSCs-derived nociceptors (iDNs) with low inter cell line difference has become available [3,4]. In patch-clamp experiments, iDNs express tetrodotoxin-sensitive (TTXs) and -resistant (TTXr) voltage-gated sodium currents with unexpected differences to their counterparts from rodent DRG. Novel mechanistic insight into the development of rare congenital disorders with an inability to feel pain or extreme pain has emerged from patient-derived nociceptor studies [5-12]. Even transdifferentiation from fibroblasts has successfully generated neuron-like cells, which express the multimodal transducer ion channel TRPV1 and can be used to study pain mechanisms [13]. However, although such differentiation protocols are well established, functional analyses of iDNs as a quality control have not sufficiently been provided to date. Despite the intriguing potential of patient-derived iDNs, surprisingly, little information is available to date regarding the functional expression of relevant other ion channels and receptors such as hyperpolarization-activated and cyclic nucleotide-gated pacemaker channels $(\mathrm{HCN})$, setting nociceptor excitability and ongoing discharge after injury [14] of voltage-gated $\mathrm{Ca}^{2+}$ channels or ionotropic $\mathrm{GABA}_{\mathrm{A}}$ receptors, which are relevant for synaptic transmission in the superficial dorsal horn [15-18] and the existence of possible synaptic connections between iDNs potentially forming neuronal networks in a dish.

To start filling this gap, we used a modified protocol for optimized human iDN differentiation [4] and recorded evoked $\mathrm{Ca}^{2+}$ transients at different time points during differentiation (D40 and D60) to obtain novel insights into the presence and function of relevant ion channels in iDNs with a specific focus on the high voltage-gated calcium channels of the $\mathrm{Ca}_{\mathrm{V}} 2$-type $\left(\mathrm{Ca}_{\mathrm{V}} 2.1-2.3\right)$, HCN channels (HCN1-4), as well as ionotropic GABA $_{A}$ receptors and directly compared human iDNs with mouse primary sensory neuron cultures.

\section{Materials and Methods}

\subsection{Differentiation of Human iPSCs into Nociceptors by Small Molecule Inhibition}

The human iPSC line had been generated within the StemBANCC project (part of an Innovative Medicines Initiative) based on a commercially available fibroblast line (Lonza, Basel, Switzerland) sourced from a healthy male donor [19]. The cells were routinely cultured on cell culture plastic ware (Greiner, Kremsmünster, Austria) coated with a murine ECM preparation (Matrigel ${ }^{\mathrm{TM}}$ at $8 \mu \mathrm{g} / \mathrm{cm}^{2}$, Corning). Cells were fed daily with mTeSR1 medium (STEMCELL Technologies) and passaged twice a week by calcium withdrawal (0.02\% Ethylenediaminetetraacetic acid (EDTA) in phosphate-buffered saline (PBS). The cells were used from the earliest available passage number (P24) up to P40 maximum.

Differentiation of human iPSCs to iDNs was performed by dual SMAD inhibition, leading to neural crest-like cells followed by an overlapping inhibition of glycogen synthase kinase 3 (GSK3 $\beta$ ), vascular endothelial growth factor (VEGF), and Notch signaling (3i inhibition), and finally long-term maintenance in neurobasal medium infused with the neurotrophic factors glial cell line-derived neurotrophic factor (GDNF), nerve growth factor (NGF), and brain-derived neurotrophic factor (BDNF), as firstly described by Chambers, Qi, Mica, Lee, Zhang, Niu, Bilsland, Cao, Stevens, Whiting, Shi and Studer [4]. This protocol was adapted by using 8 days rather than 6 days of $3 \mathrm{i}$ inhibition and N2/B27 Neurobasal medium supplemented with NGF, BDNF, and GDNF (Thermo Fischer, Waltham, MA, USA) omitting NT3 for maturation of iDNs (Figure 1A). Briefly, a single cell solution of human iPSCs was prepared using TrypLE Express and $8 \times 10^{4}$ cells were seeded into Matrigel-coated 6-well plates and maintained in mTeSR1 medium. For this and all the subsequent passages, $10 \mu \mathrm{M}$ of Rho-associated coiled-coil containing protein kinase (ROCK) inhibitor (Y27632, Sigma-Aldrich, St. Louis, MO, USA) was added 
at the time of the passage, for 1 day, to increase cell survival. The human iPSC cells were maintained in mTeSR1 medium until they reached $60-70 \%$ confluency before differentiation was initiated.

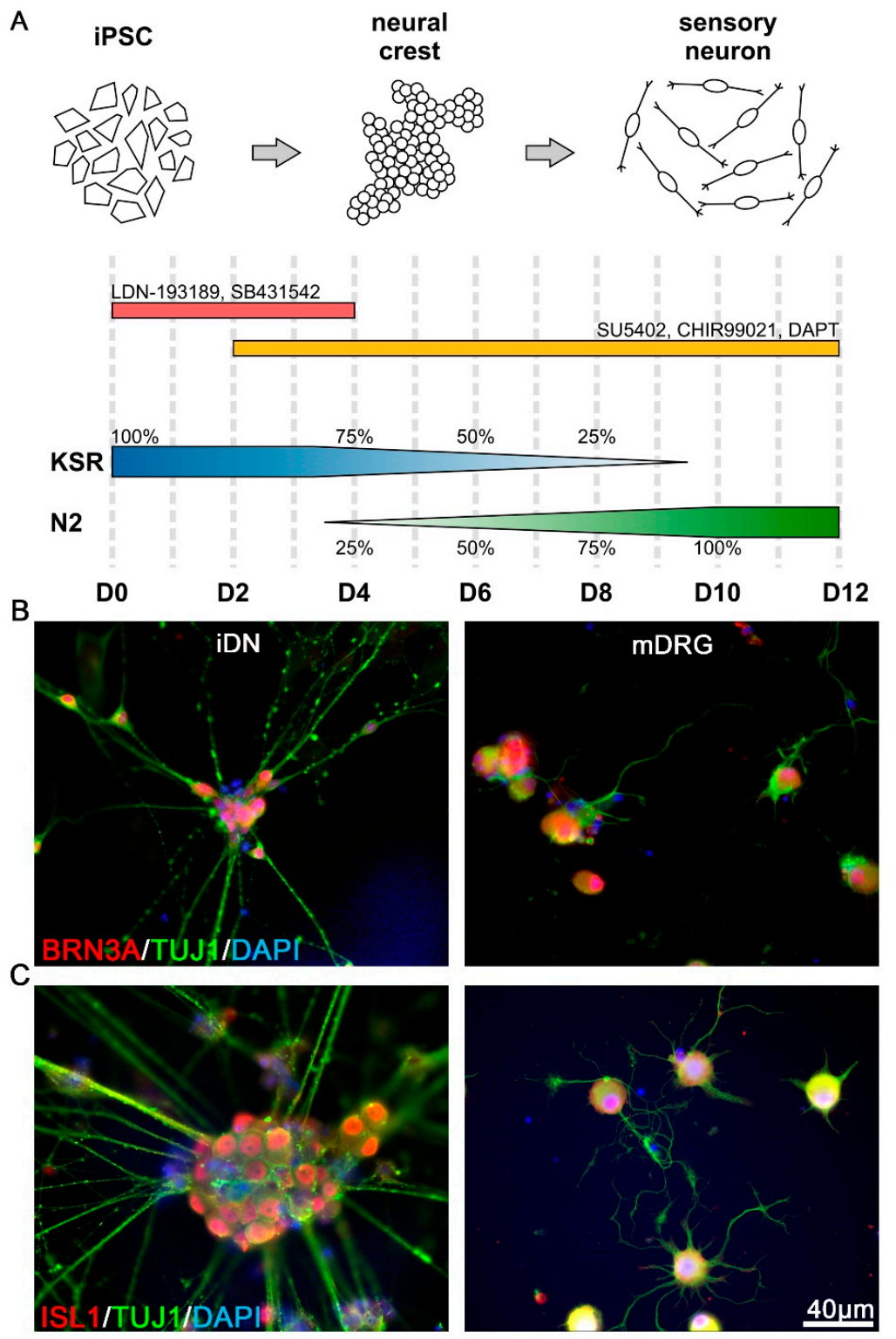

Figure 1. Differentiation of human induced pluripotent stem cells (iPSCs) into nociceptors. (A) Schematic representation of the human iPSC differentiation protocol into human iPSC-derived nociceptors (iDNs). Dual SMAD inhibition by LDN193189 and SB431542 was used to induce the neuralization process in knockout serum replacement (KSR) media. Nociceptor induction was further promoted by inhibition of GSK3 $\beta$, VEGF, and Notch signaling by SU5402, CHIR99021, and DAPT. From D12 on, iDNs were passaged and cultured for several weeks in Neurobasal Medium supplemented with $25 \mathrm{ng} / \mathrm{mL}$ NGF, BDNF, and GDNF; (B) Both iDNs and mouse dorsal root ganglion neurons (mDRG) expressed the transcription factor BRN3a. Individual iDNs robustly expressed BRN3A in the soma, similar to adult mouse neurons, $100 \%$ BRN3A+ cells were detected based on DAPI counterstaining, respectively; (C) ISL1 was strongly expressed both in iDNs and mouse neurons, typical somatic clustering of iDNs occurred with aggregates of 10-40 neurons, and 100\% ISL1+ cells were detected based on DAPI counterstaining, respectively. Cells from 2-3 individual differentiations were used, scale bar $40 \mu \mathrm{m}$. 
Subsequently, dual SMAD inhibition was initiated, thereby suppressing TGF-beta and BMP4, in knockout serum replacement (KSR) medium Knockout DMEM (Gibco), 15\% KO serum replacement (Gibco), 1\% non-essential amino acids (PAA), $2 \mathrm{mM}$ Glutamax (Gibco), 1x penicillin/streptomycin (Sigma-Aldrich), and $100 \mu \mathrm{M} \beta$-mercaptoethanol (Gibco) supplemented with $100 \mathrm{nM}$ of LDN-1931189 (Stemgent, ALK2/3 inhibitor, 100 nM, D0-D5), and $10 \mu \mathrm{M}$ SB431542 (selleckchem.com, ALK5 inhibitor, $10 \mu \mathrm{M}, \mathrm{D} 0-\mathrm{D} 5)$ for 5 days.

Additionally, $3 \mu \mathrm{M}$ CHIR99021 (selleckchem.com, GSK3 $\beta$ inhibitor, D2-D12), $10 \mu \mathrm{M}$ DAPT (selleckchem.com, Notch inhibitor, $10 \mu \mathrm{M}, \mathrm{D} 2-\mathrm{D} 12)$, and $10 \mu \mathrm{M}$ SU5402 (Sigma-Aldrich, VEGF inhibitor; $10 \mu \mathrm{M}, \mathrm{D} 2-\mathrm{D} 12)$ were added from D2-D12. From D4 on, N2/B27 medium (Gibco Neurobasal ${ }^{\mathrm{TM}}$ medium, $^{2}$ supplemented with 1\% N2 (Gibco), 2\% B27 without Vitamin A (Gibco), and 2 mM Glutamax (Gibco)), and $1 \times$ penicillin/streptomycin (Sigma-Aldrich) was added to the KSR medium and incremented every second day by $25 \%$. For a schematic representation of the exact medium and inhibitor application, see Figure $1 \mathrm{~A}$.

On day 12, 30,000 cells were passaged onto Matrigel-coated cell culture imaging dishes (ibidi $\mathrm{GmbH}$, Munich, Germany) or glass coverslips and maintained in N2/B27 medium (exchanged every 2-3 days) supplemented with NGF (hNGF, PeproTech, 25 ng/mL), BDNF (hBDNF, PeproTech, $10 \mathrm{ng} / \mathrm{mL}$ ), and GDNF (hGDNF, PeproTech, $25 \mathrm{ng} / \mathrm{mL}$ ), for the remaining time. Alternatively, cells were cryopreserved in liquid nitrogen at D12, so that final maturation could be performed at a later time points.

Cytosine- $\beta$-D-arabinofuranoside ( $4 \mu \mathrm{M}$, Sigma-Aldrich) was administered on D14 for $\sim 24 \mathrm{~h}$ to reduce the amount of non-differentiated proliferating cells and iDNs were maintained in N2/B27 medium up to 48 days.

\subsection{Primary Sensory Neuron Culture}

Male, 10-12-week-old C57BL/6J mice were used for further experiments. Mice were housed at a constant $12 \mathrm{~h}$ light/dark cycle with ad libitum access to water and chow. Lumbar DRG explants were harvested from adult mice and primary sensory cultures prepared as previously published [20]. Briefly, after extraction, the connective tissue was removed and ganglia were incubated in Liberase Blendzyme 1 (collagenase + thermolysin, $9 \mathrm{mg} / 100 \mathrm{~mL}$ DMEM, Roche, Basel, Switzerland) for $2 \times 30 \mathrm{~min}$. Subsequently, DRGs were washed and treated with $1 \times$ trypsin-EDTA for $15 \mathrm{~min}$, followed by a washing step with TNB ${ }^{\mathrm{TM}}$ medium supplemented with L-glutamine (Invitrogen, Waltham, MA, USA), penicillin G sodium, streptomycin sulfate (Invitrogen), and protein-lipid complex (Biochrom, Harvard Bioscience Inc. Holliston, MA, USA). Dissociation of DRG was performed using a fire-polished glass pipette and non-neuronal cells were removed by centrifugation with a 3.5\% BSA-gradient. Then, sensory neurons were resuspended in $\mathrm{TNB}^{\mathrm{TM}}$ medium supplemented with $25 \mathrm{ng} / \mathrm{mL}$ NGF and plated on poly-L-lysine/laminin coated coverslips. Cells were used for immunofluorescence microscopy after 23 days of incubation at $37{ }^{\circ} \mathrm{C}$ and $5 \% \mathrm{CO}_{2}$.

\subsection{Immunofluorescence Microscopy}

The AD2 (SbAd-02-01) iPSC-derived iDNs were fixed on D26, D36, D50, and D60 in 4\% paraformaldehyde in PBS at room temperature, for $10 \mathrm{~min}$. Fixed iDNs were treated with $5 \%$ normal goat serum in PBS supplemented with $0.2 \%$ BSA and $0.2 \%$ Triton X-100, for $30 \mathrm{~min}$. Primary antibodies were applied at $4{ }^{\circ} \mathrm{C}$ overnight, in a humidified chamber, and detected by fluorochrome-conjugated secondary antibodies (Alexa goat anti-rabbit A594 (\#A32740), goat anti-mouse A594 (\#A32742), goat anti-rabbit A488 (\#A32731), and goat anti-mouse A488 (\#A32723), 1:4000, Invitrogen). Primary antibodies used were anti-synapsin (1:1000, mouse monoclonal, Synaptic Systems (SySy); \#106011 reference [21]); anti-BRN3A (1:500 rabbit polyclonal, SySy, \#411003, reference [22]); anti-ISL-1 (1:500, rabbit polyclonal, SySy, \#406003 reference [23]); anti-Cav2.1 (1:1000, rabbit polyclonal, SySy, \#152103 k.o verified); anti-Cav2.2 (1:1000, rabbit polyclonal, SySy, \#152313 reference [24]); anti-Cav2.3 (1:1000, rabbit polyclonal, SySy, \#152403 reference [25]); anti-RUNX1 (1:200, rabbit polyclonal, Abcam, \#23980 
reference [26]); anti-p75 (1:200, rabbit polyclonal, Abcam, \#AB52987 reference [27]); anti-NKCC3 (1:500, rabbit polyclonal, Thermo Fisher Scientific \#PA5-56975); anti-TRPV1 (1:200, rabbit polyclonal, Alomone Labs, \#ACC-030 reference [28]); anti-TUJ1 (1:600, mouse monoclonal, R\&D Systems, \#MAB1195 reference [29]); anti-GABA $A_{A} R$ ( $\beta 2,3$ chain, representing the most abundant subunit chains of $\left.G_{A B A} R s\right)$ (1:1000, mouse monoclonal, Chemicon, \#MAB341 reference [21]); and anti-HNC1-4 (1:600, Alomone Labs, HCN1 \#APC-056, HCN2 \#APC-030, HCN3 \#APC-057, and HCN4 \#APC-052, reference [30]). Nuclei were counterstained with DAPI (4',6-diamidino-2-phenylindol) 1:10,000, (Thermo Fisher Scientific). Images were recorded using an Axioimager 2 Microscope (Carl Zeiss Microscopy) with cooled CCD camera (SPOT Imaging Solutions). Average fluorescence intensities were quantified using Metaview software (version 7.8.0.0, Molecular Devices, LLC, San Jose) with the line scan plug-in to quantify fluorescent intensity along a defined line cutting the individual axonal structures.

\subsection{Microfluorimetric $\mathrm{Ca}^{2+}$ Measurements}

The $\mathrm{Ca}^{2+}$ measurements of iDNs were performed as we previously described [31]. The iDNs were loaded with $3 \mu \mathrm{M}$ of Fura-2 AM (Invitrogen) in extracellular solution (ECS) containing as follows: $145 \mathrm{mM} \mathrm{NaCl}, 5 \mathrm{mM} \mathrm{KCl}, 2 \mathrm{mM} \mathrm{CaCl} 2,1 \mathrm{mM} \mathrm{MgCl}, 10 \mathrm{mM}$ D-glucose, and $10 \mathrm{mM}$ HEPES with $\mathrm{pH}$ adjusted to 7.3 with $\mathrm{NaOH}$, for $30 \mathrm{~min}$, at $37^{\circ} \mathrm{C}$, in $5 \% \mathrm{CO}_{2}$. Subsequently, cells were washed with ECS. Calcium imaging was performed on an IX71 microscope (Olympus) with 20×/0.85 N.A. oil-immersion objective. The Omicron LEDHUB System was used for excitation of Fura-2 at $340 \mathrm{~nm}$ and $380 \mathrm{~nm}$ wavelengths, and emission was detected at $510 \mathrm{~nm}$. The F340/F380 excitation ratio was calculated after background correction. The baseline was recorded over $10 \mathrm{~s}$ prior to each treatment. To elucidate treatment-induced $\mathrm{Ca}^{2+}$ transients in an unbiased way, an increase of 10\% over baseline F340/F380 ratio was applied as the threshold. The percentage of active cells was calculated and compared for each treatment and time point.

\subsection{Statistical Analyses}

Statistical analyses were performed in Python (v3.8; https://www.python.org) using the open-source packages "scipy.stats" (https://www.scipy.org), "numpy" (https://www.numpy.org), and "pandas" (https://pandas.pydata.org), as well as GraphPad Prism (v8) (GraphPad Software, San Diego). Data are presented as mean \pm standard error of the mean (SEM) or as percentages. Two-way ANOVA with Dunett's correction for multiple comparisons or Chi-square test without Yates correction was applied as indicated. The significance threshold was set to $p<0.05$. For graphical illustration, Adobe Photoshop CC 2020 (Adobe San Jose, CA, USA), CorelDraw v8 (Ottawa, ON, Canada), and the Python packages "Seaborn", "Matplotlib", and "Pandas" were used.

\section{Results}

\subsection{Expression of Early Transcription Factors Regulating Sensory Differentiation}

Characterization of early stage iDNs and sensory neurons obtained from mature mouse DRG was performed by quantification of BRN3A and ISL1 expression, which are two transcription factors with critical implications for sensory neuron development [32]. In line with previous reports, immature iDNs (D26), as well as mouse sensory neurons, showed a robust somatic expression of both transcription factors (Figure 1B,C) [33]. The iDNs showed a stable somatic expression of BRN3A (Figure 1B), and ISL1 expression was detectable similar to BRN3A in $100 \%$ of iDNs depending on the DAPI counterstaining with a threshold of $>10 \mu \mathrm{m}$ as a positive selection criterion (Figure 1C). Furthermore, D26 iDNs showed a characteristic somatic clustering, as described previously [4]; neurites stained positive for the neuron specific $\beta$-III tubulin marker TUJ1 and putative axo-axonal synaptic varicosities were visible. 


\subsection{RUNX1 and p75 Expression Reveal a Nociceptor Neuron Phenotype}

Runt-related transcription factors (RUNX) play essential roles during the development of somatosensory neurons. In particular, RUNX1 determines the nociceptor phenotype for pain, itch, and thermal sensation in mature nociceptive neurons [34,35]. RUNX1 together with the T-cell leukemia homeobox 3 protein (TLX3) regulate the development and survival of TrkA expressing nociceptive sensory neurons [36,37], and RUNX1 also plays a pivotal role for the development of low-threshold C-mechanoreceptors (CLTMs) [38]. However, RUNX1 expression persists longer in RET+ neurons during development, but extinguishes in adult TrkA+ neurons [34]. In the current study, we detected stable expression of RUNX1 both in iDNs and mouse neurons (Figure 2A). RUNX1 was expressed in all TUJ1 positive iDNs (Figure 2B). In order to further dissect the phenotype of iDNs, the low affinity nerve growth factor receptor p75 as a broadly accepted nociceptive marker was included in the characterization [39-41] and p75 was shown to be required for the sensory neuron diversity by potentiating RET signaling [42], as well as RET was shown to be activated subsequently after RUNX1 expression in previously established iDN differentiation protocols [4]. We detected a robust expression of p75 in iDNs (Figure 2C), and $\sim 79 \%$ of iDNs showed p75 abundance as compared with mouse DRGs $(\sim 64 \%)$ (Figure $2 \mathrm{D})$, and therefore in conjunction with the high expression of RUNX1 resembling a non-peptidergic iDN phenotype (Figure 2C,D). Consequently, the gross majority of differentiated iDNs developed a nociceptive phenotype which resembled well the phenotype of small size sensory neurons obtained from adult mice [34].
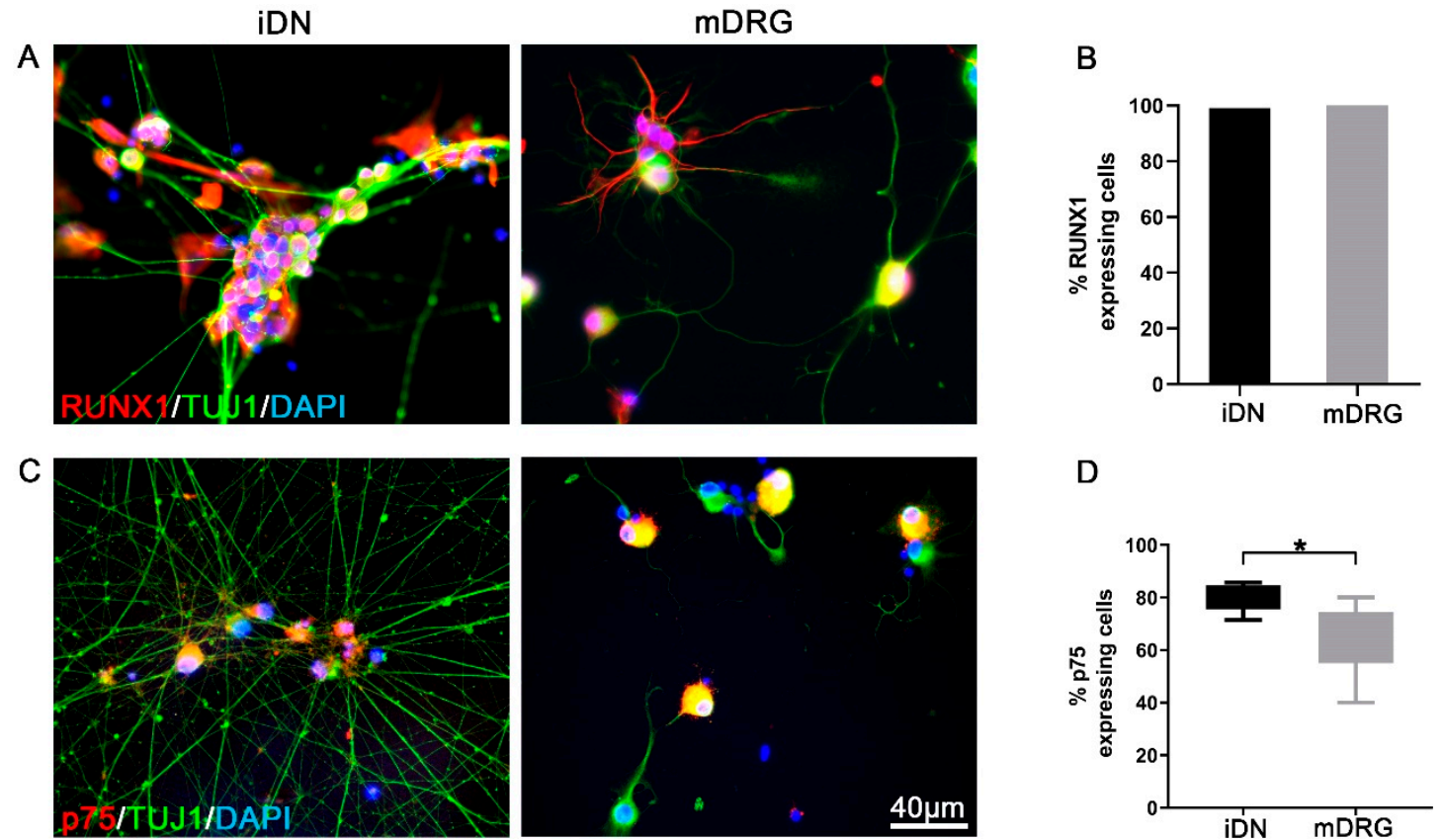

Figure 2. RUNX1 and p75 expression indicative of nociceptor-like phenotype of iDNs. (A) Representative image of D36 iDNs as compared with mouse neurons (mDRG); (B) Both iDNs and mouse DRGs showed a robust RUNX1 soma expression pattern in $100 \%$ of DAPI+ cells. Counting threshold was set to $>10 \mu \mathrm{m}$ based on DAPI counterstaining; (C) p75-IR cells in D36 iDNs as compared with mouse neurons; (D) $\sim 79 \%$ of iDNs were positive for $\mathrm{p} 75$, whereas only $\sim 64 \%$ were positive in mouse neuron cultures. Cells from 2-3 individual differentiations were used, two-tailed t-test, ${ }^{*} p=0.025$, error bars indicate SEM, scale bar $40 \mu \mathrm{m}$.

\subsection{TRPV1 Experession in iDNs}

The superfamily of the transient receptor potential (TRP) channels has emerged as the largest group of molecules involved in the transduction of various physical stimuli into neuronal signals in primary sensory neurons [43]. Here, we focused on the noxious heat sensitive channel TRPV1 that 
can be activated by the vanilloid capsaicin, the main pungent of hot chilli peppers. Stable TRPV1 immunoreactivity (IR) was detected in iDNs and mouse DRGs (Figure 3A-C). By performing triple stainings for TRPV1/TUJ1/DAPI, we identified $\sim 44 \%$ of all iDNs to robustly express TRPV1 in the soma at D36, stagnating to $\sim 46 \%$ at D62 as compared with $\sim 74 \%$ in mouse DRGs (Figure 3D). This result could indicate a mature iDN phenotype at D36. Interestingly, putative TUJ1-IR synaptic varicosities that stained positive for TRPV1 were visible along neurites as quantified by line scan analysis (Figures 3B and 4). To further evaluate these synaptic varicosities, a staining for the presynaptic vesicle-associated protein, synapsin, an early marker for presynaptic vesicle recruitment, was performed [44]. Costaining of synapsin with the toxin phalloidin, an $\mathrm{F}^{+}$actin neurite marker, revealed synapsin-positive varicosities in iDNs, thereby, indicating that synaptogenesis, indeed, occurred in these neurons (Figure 4). The majority of the axonal varicosities in iDNs showing phalloidin-IR were also immunoreactive for synapsin both in regions distal and proximal to the next iDN cluster (Figure 4A,B).
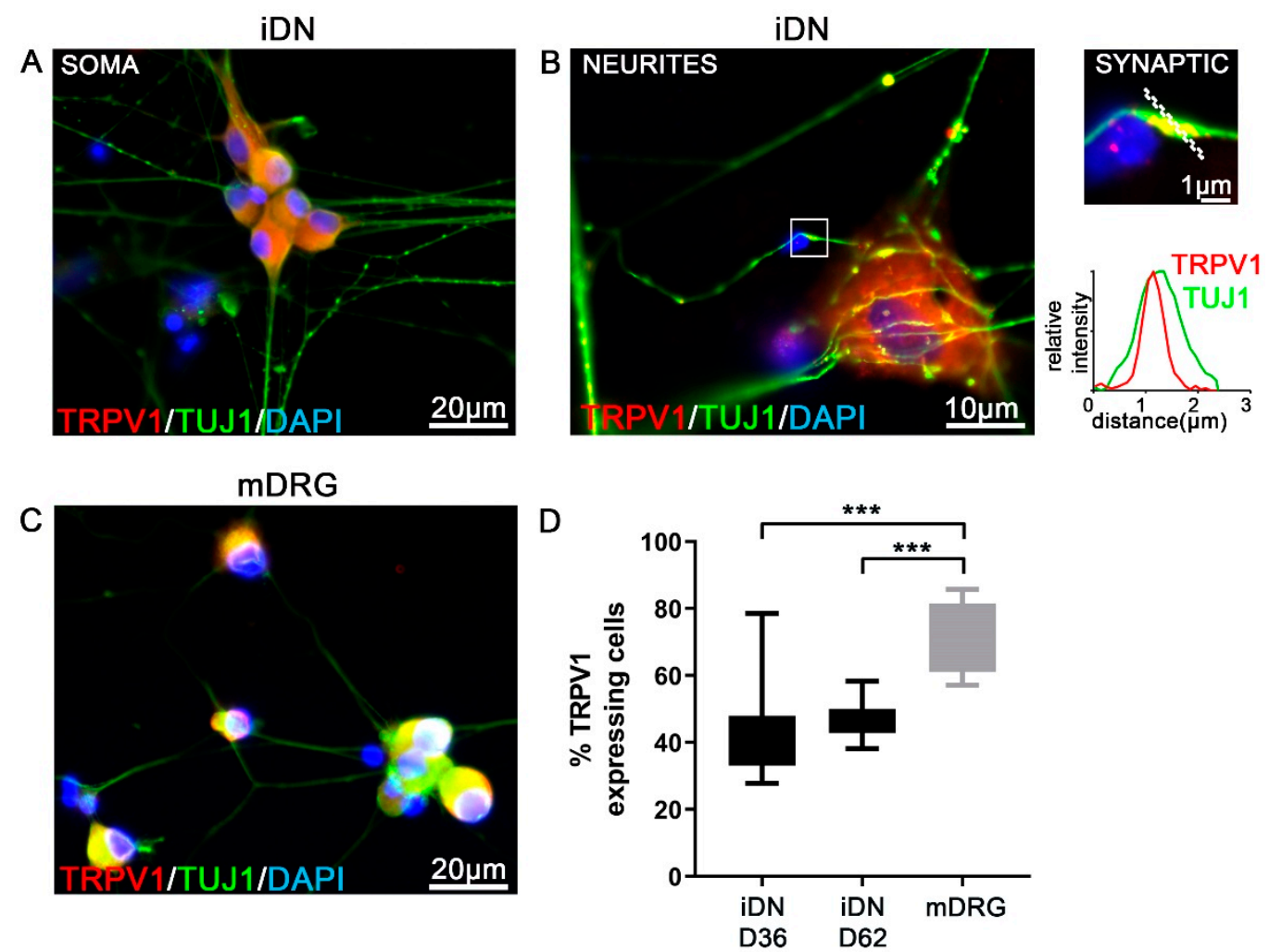

Figure 3. Robust TRPV1 expression in iDNs. (A) Robust TRPV1 expression in D36 iDNs, counting threshold was set to $>10 \mu \mathrm{m}$ based on DAPI counterstaining; (B) Neurite regions revealed TRPV1 abundance in individual TUJ1-IR varicosities. Relative fluorescence intensity measurements using line scans for individual TUJ1-IR clusters (enlargement) revealed putative synapses including TRPV1 clustering in synaptic regions, line scan was set to $3 \mu \mathrm{m}$; (C) Mouse DRG neurons (mDRG) were used as controls; (D) Quantification of TRPV1+ cells based on the total number of DAPI+ cells in D36 and D62 iDNs. By D36, already $\sim 44 \%$ of iDNs showed a strong TRPV1 expression stagnating to $\sim 46 \%$ by D62. A significantly higher percentage of $\sim 74 \%$ of mouse neurons stained positive for TRPV1. 2-3 individual differentiations were used, one-way ANOVA with Dunett's multiple comparisons, ${ }^{* * *} p<0.001$, error bars indicate SEM. 

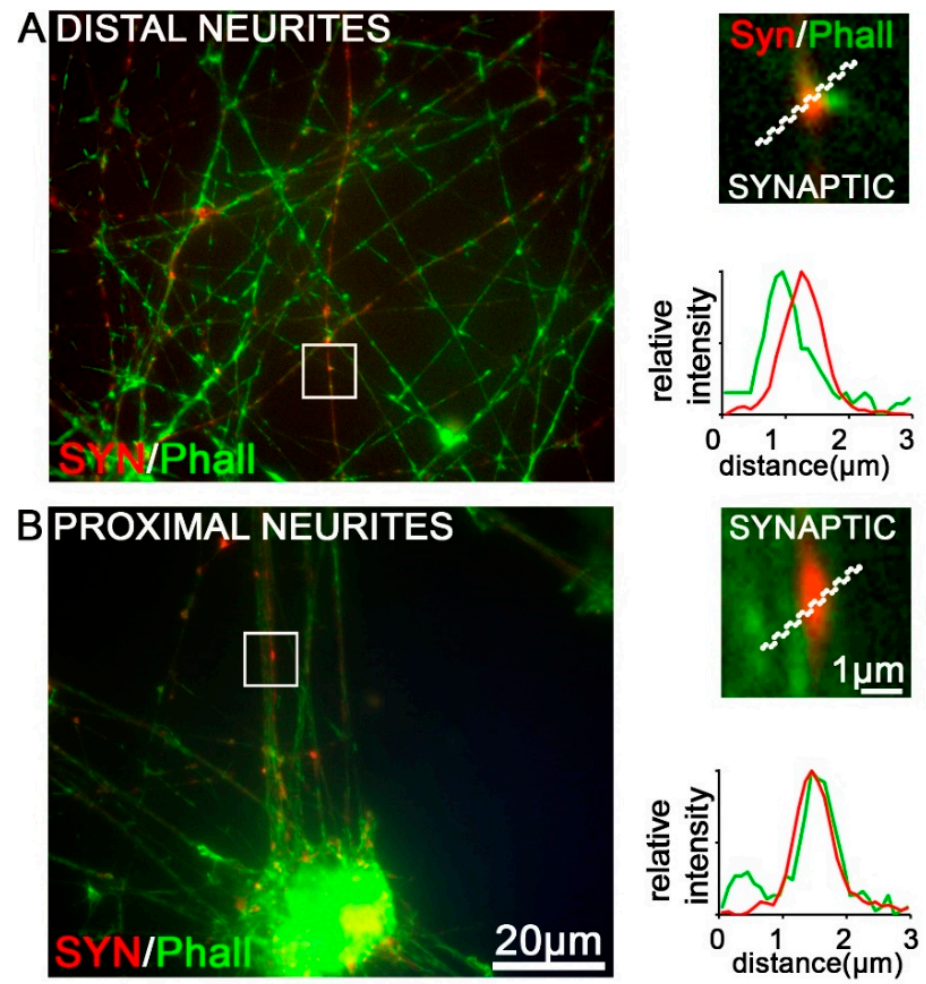

Figure 4. Characterization of synaptic varicosities on D50 iDNs. iDNs were labeled with a synapsin antibody costained for phalloidin 488 (green) indicating F-actin ${ }^{+}$axonal structures. Magnifications highlight individual synaptic varicosities, putative axo-axonal synapses (red) both in regions of distal (A) and proximal neurites (B). 2-3 individual differentiations were used, bar $20 \mu \mathrm{m}, 1 \mu \mathrm{m}$ (enlargement), line scan was set to $3 \mu \mathrm{m}$.

\subsection{Expression of Pacemaker Channel HCN1-3 but Not HCN4 in iDNs and mDRG Neurons}

Hyperpolarization-activated cyclic nucleotide-gated $(\mathrm{HCN})$ channels drive the repetitive firing in nociceptive neurons, and thus play a crucial role in pace making activity [45]. To further underpin the mature phenotype of iDNs, expression of HCN1-4 was assessed on D26 iDNs and mouse sensory neurons. Immunofluorescent analysis revealed a strong HCN1-3-IR (Figure 5A-C) but not HCN4-IR (Figure 5D) both in D26 iDNs and mouse neurons. In order to explore whether this expression of pacemaker channels was functionally relevant, the spontaneous activity of iDNs was assessed by microfluorometric calcium measurements (Figure 5E). Approximately $70 \%$ of iDNs exhibited spontaneous $\mathrm{Ca}^{2+}$ transients indicative of spontaneous action potential firing, which was defined by a spontaneous calcium influx, increasing the peak to baseline F340/F380 ratio by a factor of 1.1 in iDNs. Each peak was independently evaluated to a newly calculated baseline preceding the peak $30 \mathrm{~s}$ in advance, to compensate for general baseline transient changes (Figure 5E). 

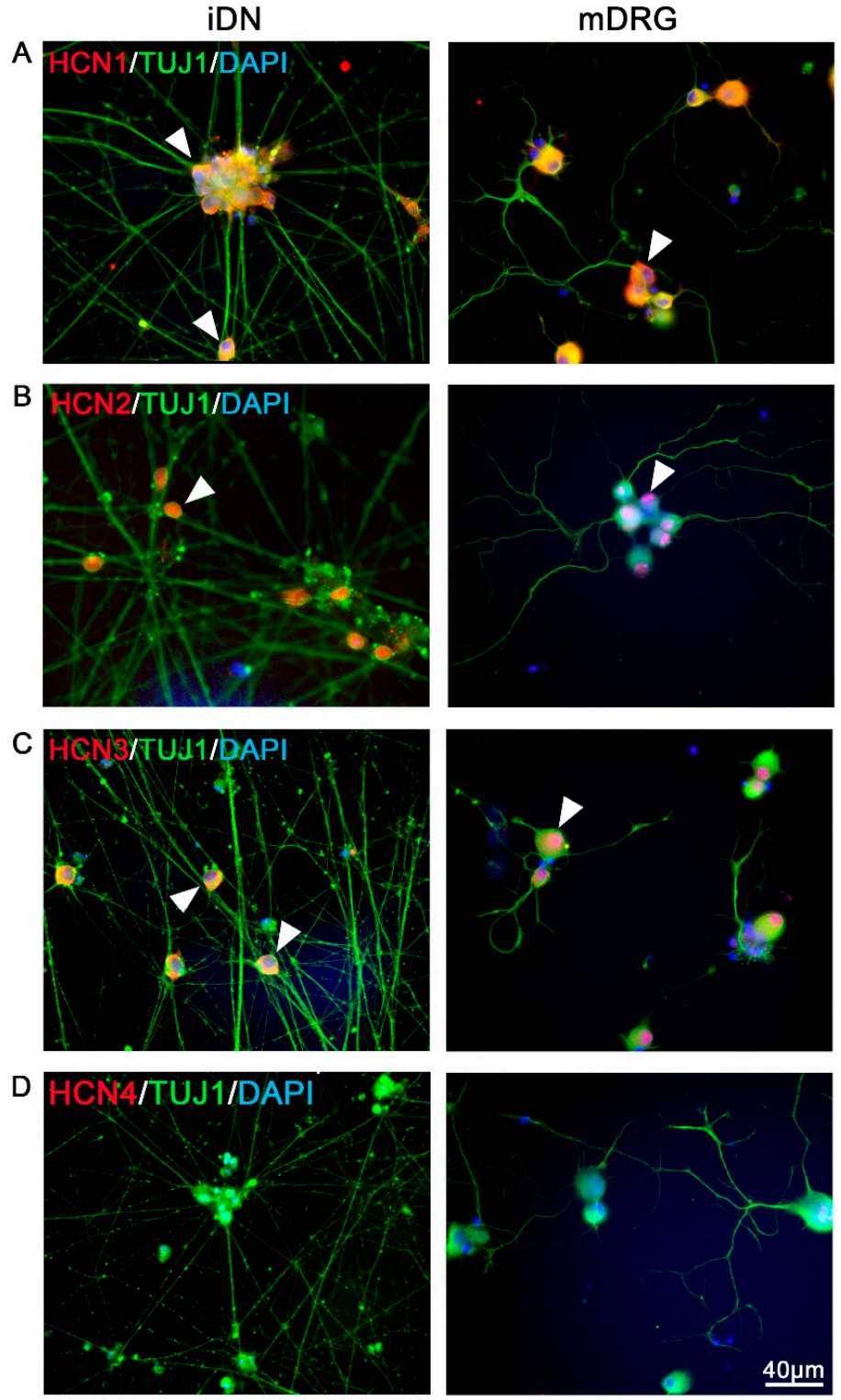

E

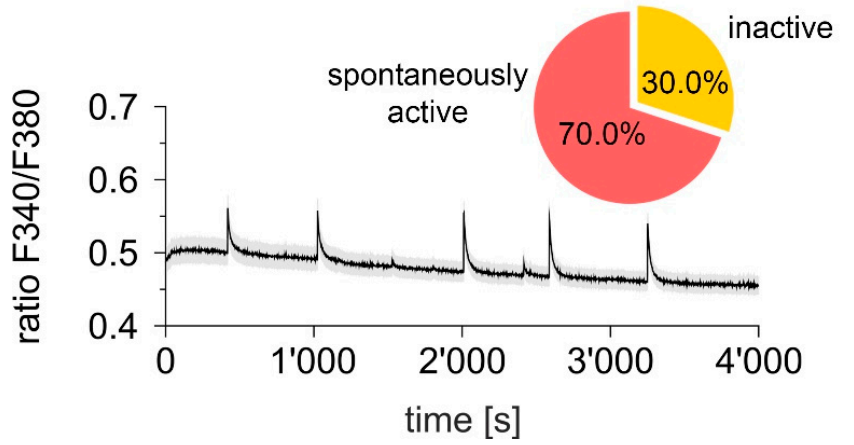

Figure 5. Ongoing activity and expression of pacemaker channels HCN1-3 in iDNs. (A-C) Immunoreactivity of HCN1-3 was reproducibly detected both in iDNs and mDRG neurons (arrowheads). 100\% of cells showed immunoreactivity of HCN1-3 based on DAPI counterstaining, respectively; (D) HCN4 was not expressed in D26 iDNs or in mDRG controls, scale bar $40 \mu \mathrm{m}$; (E) iDNs exhibit a low baseline $\mathrm{Ca}^{2+}$ concentration but regular transient increases (ratio F340/F380) indicative of spontaneous discharge activity $(n=30)$. Pie chart indicating the percentage of spontaneously active iDNs $(70 \%)$ as compared with inactive iDNs (30\%) at D60. 


\subsection{Expression of $\mathrm{Ca}_{V} 2$ High Voltage-Activated Calcium Channels}

Ion channels have proven to be indispensably important for synaptic, and thus, consequently, for nociceptor function. In addition to voltage-gated sodium channels, which have been extensively studied and described as nociceptive ion channels $[5,8,9,12,46-49]$, here, we focused on high voltage-activated calcium channels of the $\mathrm{Ca}_{\mathrm{V}} 2.1 / \mathrm{PQ}$-type, $\mathrm{Ca}_{\mathrm{V}} 2.2 / \mathrm{N}$-type, and $\mathrm{Ca}_{\mathrm{V}} 2.3 / \mathrm{R}$-type. All three high voltage activated $\mathrm{Ca}_{V} 2$ channels contribute to nociception [50], and therefore were included in the present comparison between human iDNs (D50) and mouse DRG neurons. We found robust expression of all three $\mathrm{Ca}_{\mathrm{V}} 2$ channels, i.e., $\mathrm{Ca}_{\mathrm{V}} 2.1 / \mathrm{PQ}$-type, $\mathrm{Ca}_{\mathrm{V}} 2.2 / \mathrm{N}$-type, and $\mathrm{Ca}_{\mathrm{V}} 2.3 / \mathrm{R}$-type, which were clustering along neuronal TUJ1+ neurites (Figure 6A-F). In order to address the subcellular location of individual $\mathrm{Ca}_{\mathrm{V}} 2$ channel subtypes, in particular, in putative synaptic varicosities of iDNs, line scan measurements were performed. Relative fluorescence intensity measurements revealed putative synaptic localization patterns of individual $\mathrm{Ca}_{\mathrm{V}} 2$ channel subtypes (red) on TUJ1-IR synaptic varicosities, indicating putative axo-axonal synaptic connections between differentiated iDNs (Figure 6A-C). This was strikingly different in mouse neuron cultures, where stable Cav2 channel expression was found on TUJ-IR neurites, however, no putative axo-axonal synaptic varicosities were observed (Figure 6D-F).

iDN
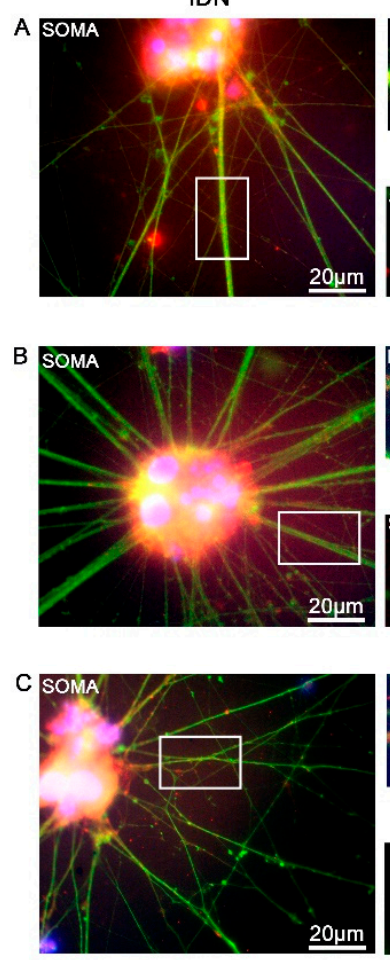

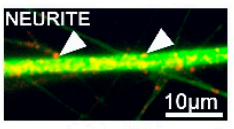

Cav2.1/TUJ1
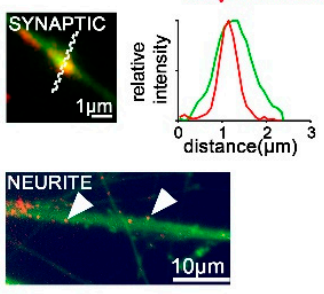

$10 \mu \mathrm{m}$
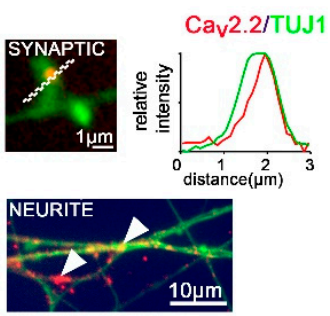

Cav2.3/TUJ1
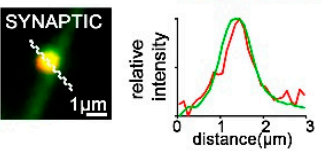
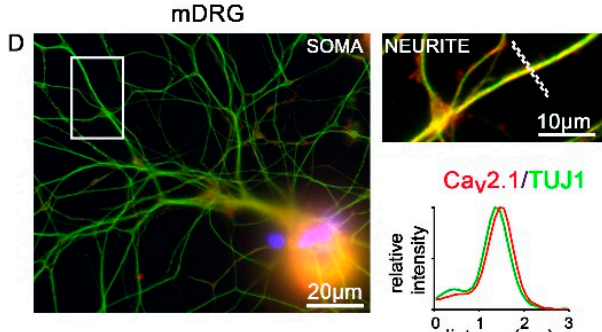

Cav2.1/TUJ1
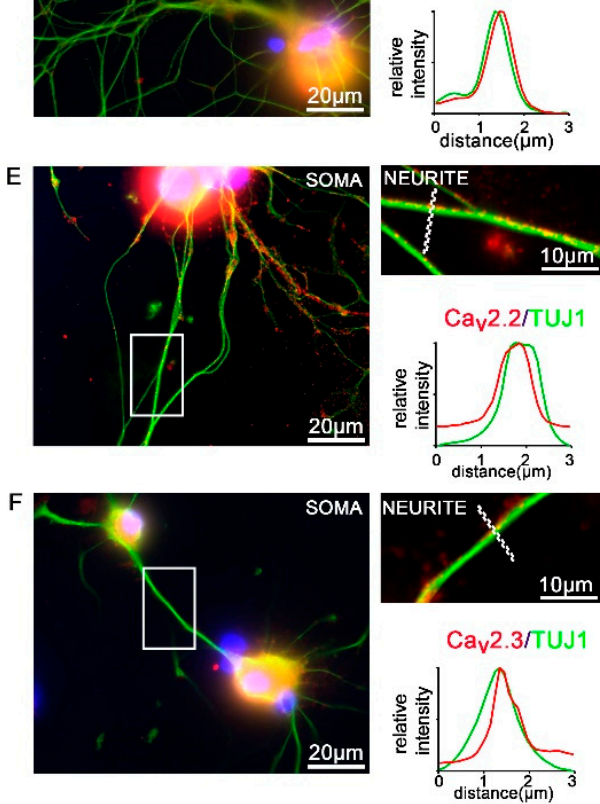

Figure 6. Expression of $\mathrm{Ca}_{\mathrm{V}} 2$ high voltage activated calcium channels. (A-C) D50 iDNs showed robust expression of all $\mathrm{Ca}_{\mathrm{V}} 2$ high voltage activated calcium channels in regions of the soma, neurites, as well as axonal varicosities. Arrowheads indicate individual (A) $\mathrm{Ca}_{\mathrm{V}} 2.1 / \mathrm{PQ}$-type, (B) $\mathrm{Ca}_{\mathrm{V}} 2.2 / \mathrm{N}$-type, and (C) $\mathrm{Ca}_{\mathrm{V}}$ 2.3/R-type clusters along neurite structures of iDNs. Line scan measurements for individual $\mathrm{Ca}_{\mathrm{V}} 2$ clusters on TUJ1-IR+ varicosities revealed their location within putative synaptic structures in iDN cultures, line scan was set to $3 \mu \mathrm{m}$. (D-F) Mouse neurons (mDRG) served as controls, line scans performed on neurite segments, no axonal varicosities were detected, 2-3 individual differentiations, scale bars $20 \mu \mathrm{m}$ (overview, soma), $10 \mu \mathrm{m}$ (enlargement, axon), $1 \mu \mathrm{m}$ (axonal varicosities, putative synapses).

\subsection{GABAA Receptors and Transporters in iDNs}

In the adult peripheral nervous system, activation of ionotropic $G_{A B A}$ receptors $\left(G A B A_{A} R\right)$ can cause neuron excitation because of the high concentration of intracellular chloride in these neurons 
(for review see [51]). Potassium-chloride cotransporters (KCCs) appear to play a critical role in hyperalgesia and allodynia following peripheral inflammation or nerve injury [52]. As an example, we investigated localization patterns of $K C C 3$ and GABA $_{A} R(\beta-2 / 3$ subunit)-IR in iDNs and mouse sensory neurons. Whereas both proteins were expressed in iDNs and mouse sensory neurons, D40 iDNs showed a different co-clustering pattern as indicated by line scan analysis of neurite segments (Figure 7A,B). This could indicate that D40 iDNs show a lower degree of KCC3/GABA $\mathrm{R}$ co-clustering, however, whether this is functionally relevant will be addressed in further experiments.
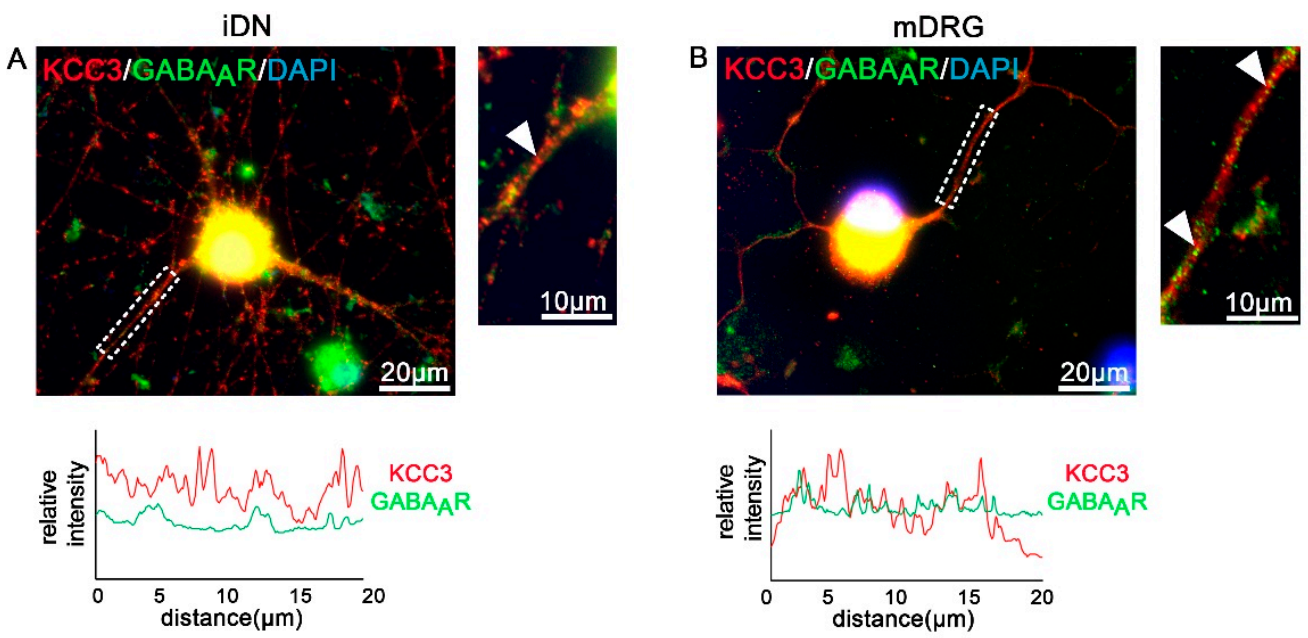

Figure 7. Quantification of $K C C 3 / G A B A_{A} R$ clustering on iDNs and mouse DRG neurons. $(\mathbf{A}, \mathbf{B})$ Both day 40 iDNs and mouse DRG neurons stained positive for KCC3-IR and GABA $\mathrm{A}$ labeling (arrow heads neurite selections). Line scan analyses on $20 \mu \mathrm{m}$ neurite structures were performed. (A) Lower intensity levels of $\mathrm{GABA}_{\mathrm{A}} \mathrm{R}$ clustering in iDNs were elucidated as compared with mouse DRGs (B). 2-3 individual differentiations, scale bars $20 \mu \mathrm{m}$ and $10 \mu \mathrm{m}$ (enlargement), line scan was set to $20 \mu \mathrm{m}$.

\subsection{Functional Characterization of iDNs}

In order to further functionally characterize iDNs, microfluorimetric $\mathrm{Ca}^{2+}$ measurements of iDNs were performed on D40 (Figure 8A-C) and D60 (Figure 8D-F). For this, cells exhibiting a neuronal morphology were selected for further analysis (D40 189 iDNs and D60 98 iDNs). Averaged time-series analysis of calcium transients of all selected iDNs revealed prominent calcium transients already on D40, after administration of $25 \mathrm{nM}$ capsaicin, $50 \mu \mathrm{M} \mathrm{GABA}$, and $25 \mathrm{mM} \mathrm{KCl}$ (Figure 8A-C). Interestingly, there was a pronounced discrepancy between the percentages of iDNs expressing TRPV1-IR (Figure 3D) and of iDNS responding to the TRPV1 activator capsaicin with fast rising $\mathrm{Ca}^{2+}$ transients indicative of $\mathrm{Ca}^{2+}$ influx (Figure 8D-F). Additionally, administration of GABA, which activates both $\mathrm{GABA}_{\mathrm{A}}$ as well as $\mathrm{GABA}_{B}$ receptors, induced depolarizations in the majority of iDNs, comparable with those found in rodent DRGs (Figure $8 \mathrm{C}, \mathrm{F}$ ).

However, no significant differences in substance induced $\mathrm{Ca}^{2+}$ transients were determined between D40 and D60, indicating a high degree of functional maturation of iDNs regarding the expression of relevant markers and ion channels already by D40, however, full functionality still lagged behind (Figure 8A-F).

Collectively, our study of human iDNs and the direct comparison to mouse sensory neurons of a selected nociceptive marker panel (summarized in Table 1) provides not only morphological evidence for human iDNs developing specific nociceptor phenotypes but, more importantly, provides converging evidence supporting their suitability as a model to study nociceptive mechanisms. 
A

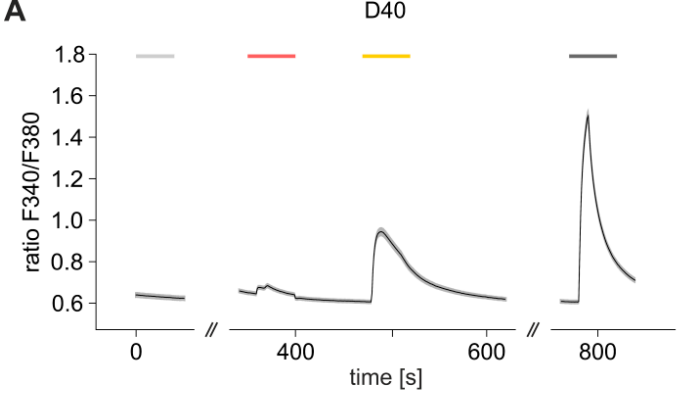

B

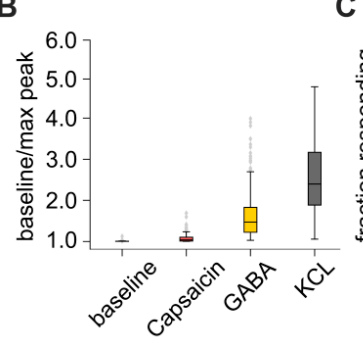

C

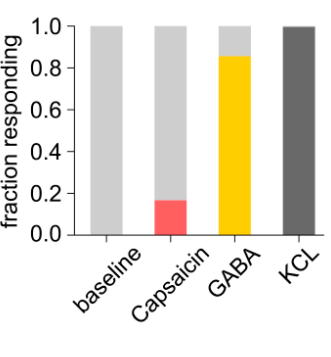

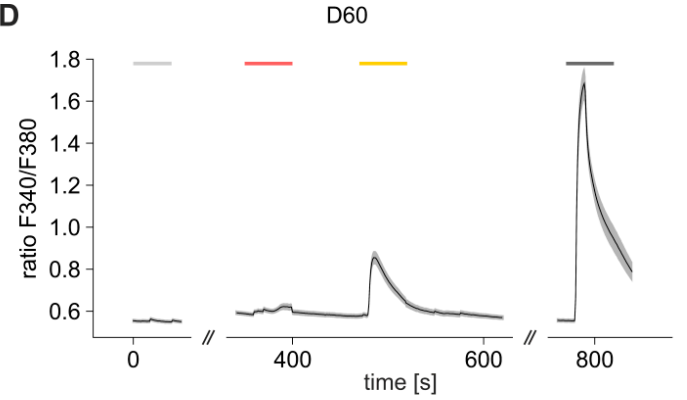

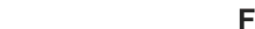

Figure 8. $\mathrm{Ca}^{2+}$ transients evoked by chemical nociceptor stimuli in iDNs on D40 (A-C) and D60 (D-F). Time-series analysis of substance induced $\mathrm{Ca}^{2+}$ transients following administration of extracellular solution (ECS, grey), capsaicin $25 \mathrm{nM}$ (red), GABA $50 \mu \mathrm{M}$ (yellow) and $25 \mathrm{mM} \mathrm{KCl}$ (dark grey) was quantified and visualized. The mean F340/F380 for each positive cell (succeeding the peak-to-baseline threshold of 1.1) was determined and substance induced reaction was compared qualitatively. The stacked bar charts $(\mathbf{C}, \mathbf{F})$ indicate the percentage of positively reacting and non-reacting cells upon administration of each individual substance. Chi-square test did not identify any significant differences between D40 and D60 ( $p$-value > 0.05).

Table 1. Summary of the used markers, level of expression, and morphological abundance in iDNs and mouse sensory neurons.

\begin{tabular}{ccc}
\hline Marker & iDN & mDRG \\
\hline BRN3A & $100 \%$ (high and low expressing cells) & $100 \%$ \\
ISL1 & $100 \%$ & $100 \%$ \\
RUNX1 & $100 \%$ (high and low expressing cells) & $100 \%$ \\
p75 & $\sim 79 \%$ & $\sim 64 \%$ \\
TRPV1 & $\sim 45 \%$ & $\sim 74 \%$ \\
SYN & positive varicosities/boutons & no varicosities/boutons \\
HCN1-3 & $100 \%$ & $100 \%$ \\
HCN4 & not expressed & not expressed \\
Cav2.1 & & expressed on neurites, no synaptic \\
Cav2.2 & expressed, synaptic localization patterns & localization patterns \\
Cav2.3 & & expressed/higher levels \\
KCC3/GABA & higher degree of colocalization \\
TUJ1/Phall & neurites and varicosities/boutons & only on neurites \\
\hline
\end{tabular}

\section{Discussion}

Over the past decades, rodent models have been indispensable for pain research and have largely contributed to our current knowledge about molecular mechanisms of pain [53]. However, the field has sought alternatives due to a limited translation to the human disease situation caused by species-to-species differences [54]. For many years, research on human tissues could only be performed by using post-mortem tissue, which faces restrictions, in particular, as far as functional assays are concerned [1]. An emerging opportunity to circumvent the apparent translational paresis 
in pain research is the application of new model systems derived from human iPSCs that allow directed cell-type specific programming into iDNs. This approach has become applicable on a larger scale after robust differentiation protocols became available [4,55-57]. First attempts to personalize research towards pain disorders arising from gain-of-function mutations of voltage-gated $\mathrm{Na}^{+}$channels have exploited these possibilities [58,59]. More recently, iDN transdifferentiation protocols have speeded up the use of iDNs from patients suffering from monogenetic pain disorders for which, so far, mechanistic insight is unavailable [60]. Specific immunohistochemical markers such as RUNX1, p75, BRN3A, and TRPV1 generally mark the successful transition of human iPSCs towards a nociceptor phenotype $[4,34,42,43]$ and have proven the successful differentiation of iDNs in the current study. However, the functional characteristics of iDNs and their similarities to human nociceptors are still insufficiently explored. In the present study, therefore we provide a detailed characterization of iDNs differentiated from human iPSCs and functional evidence how iDNs partially resemble their rodent counterparts by a comparison with mouse DRG neurons.

In addition to voltage-gated $\mathrm{Na}^{+}$channels, which have been extensively exploited for hereditary painful neuropathies $[5,8,9,12,49]$, all high voltage-activated $\mathrm{Ca}_{\mathrm{V}} 2$ channels have important implications in pain signaling, as reviewed by Bourinet, Altier, Hildebrand, Trang, Salter and Zamponi [50]. The impact of $\mathrm{Ca}_{\mathrm{V}}$ channels on nociception has been elegantly demonstrated by the application of specific toxins blocking each channel. For example, the Cav2.1 channel blocker agatoxin, a spider toxin, was shown to inhibit inflammatory pain of the knee joints [61]. The $\mathrm{Ca}_{\mathrm{V}} 2.2 / \mathrm{N}-\mathrm{type}$ channel blocker conotoxin-GVIA, a sea snail toxin, elicits potent suppression of pain when delivered intrathecally in rodents [62] and the $\mathrm{Ca}_{\mathrm{V}} 2.3$ blocker SNX-482, another spider toxin, additionally elicited analgesia in models of neuropathic pain [63]. In iDNs, we detected a robust expression of all $\mathrm{Ca}_{\mathrm{V}} 2$ high voltage-activated calcium channels at TUJ1-IR axonal varicosities, indicative of synapse formation. These synaptic characterization data are important, considering the central roles of voltage-gated calcium channels and their accessory $\alpha_{2} \delta$ subunits playing a critical role for neurotransmitter release at presynaptic terminals and further representing direct targets for analgesic drugs including Gabapentinoids [64-66]. In contrast, mouse nociceptors showed $\mathrm{Ca}^{2+}$ channel expression patterns on axonal segments but no putative synaptic boutons, suggesting that adult nociceptors do not form synaptic networks in culture.

The superfamily of the transient receptor potential (TRP) channels has emerged as the largest family of transducer ion channels in primary sensory neurons [43]. Here, we focused on the nociceptor-specific, heat sensitive TRPV1 channel which was detectable in the somata of $\sim 44 \%$ of all iDNs by D36, $46 \%$ by D62, and $74 \%$ of mouse sensory neurons. The discrepancy between the percentages of iDNs expressing TRPV1-IR and of iDNs responding to the TRPV1 activator capsaicin was likely to be caused by TRPV1 sequestration in vesicles by the interaction with t-SNARES of the Vit1b type [67]. Indeed, TRPV1 and the transient receptor potential ankyrin1 (TRPA1) were found in VAMP1 containing vesicles of cultured sensory neurons [68], and thus chemical nociceptor stimulation could not target these fractions.

The iDN processes developed structural signatures resembling synaptic varicosities. Interestingly, $\mathrm{Ca}_{\mathrm{V}} 2$ and also TRPV1 immunoreactivity were found in such synapsin-positive varicosities in iDNs. This finding is in accordance with previous reports that demonstrated a role of TRPV1 in synaptic vesicle recycling $[69,70]$. The synapses and their key regulatory proteins, in the active zones including $\mathrm{Ca}_{V} 2$ VGCCs with their auxiliary subunits as part of the synaptic release machinery, are the communication platforms between neurons, and thus critical targets for several analgesics $[50,64]$. Accordingly, this species-to-species difference could represent an important pathophysiological bias between rodent and human pain model systems and needs to be addressed in full detail.

Our results are also in line with previous reports on HCN1-3 channels that were found in different flavors in small and large diameter rat DRG neurons, with nociceptors expressing, in particular, HCN2, whereas HCN4 levels were negligible [71,72]. These data indicate that, already at D36, iDNs developed a relatively mature nociceptive phenotype or even resembled a suitable model for neuropathic pain, 
since expression patterns of $\mathrm{HCN}$ channels and signatures of ongoing activity, which typically develop after nerve injury, were observed in D26 iDNs [14,73-81].

Several functionally relevant receptors which are located in iDNs such as HCN channels, the multimodal transducer channel TRPV1, as well as ionotropic $\mathrm{GABA}_{\mathrm{A}} \mathrm{R}$, are expressed on nociceptor peripheral nerve terminals, slow fiber axons, cell bodies in the DRG, and their central processes connecting to neurons in the spinal dorsal horn [82]. These receptors can serve dual functions. For example, GABA is synthesized in fibroblasts and likely liberated upon injuries causing skin disruption, and $\mathrm{GABA}_{\mathrm{A}}$ receptor-mediated nociceptor excitation is well accepted [83,84]. In addition, $\mathrm{GABA}_{\mathrm{A}}$ receptors, at presynaptic terminals in the superficial dorsal horn, can be targeted for presynaptic inhibition, which sets a brake to mechanical hypersensitivity [85]. However, whether GABA has excitatory or inhibitory effects largely depends on the actual concentration of intracellular chloride in these neurons (for review see [51]). Potassium-chloride cotransporters (KCCs) appear to play a critical role in hyperalgesia and allodynia following peripheral inflammation or nerve injury, and typically the $\mathrm{KCC} 3$ transcript is expressed at higher levels than the other cation- $\mathrm{Cl}^{-}$cotransporter transcripts in adult DRG neurons [52]. Expression of $\mathrm{KCC} 3$, as reported, further suggests that iDNs resembled a relatively mature nociceptor phenotype.

\section{Conclusions}

Altogether, iDNs generated with the modified protocol developed a surprisingly far developed phenotype, which, from D36, combined attributes of nociceptive terminals such as TRPV1 transducer channels with the machinery that is located at presynaptic terminals of primary afferent neurons including all types of high voltage activated $\mathrm{Ca}_{\mathrm{V}} 2$ channels. These findings underpin the enormous potential of these neurons as an animal-free alternative for future personalized pain research, to unveil pathophysiological mechanisms in humans and for unbiased, disease-specific, and patient-oriented drug development.

Author Contributions: Conceptualization, execution of experiments and analysis: M.K., C.L.S, M.Z., L.S; methodology: M.Z.; C.L.S., G.K.; software analysis: C.L.S.; M.Z; validation: C.L.S., K.K.K., M.K.; investigation: C.L.S., L.S., M.Z.; resources J.L., M.K.; writing-original draft preparation: C.L.S.; writing-review and editing: C.L.S., M.Z., K.K.K., M.K.; supervision: M.K.; funding acquisition: M.K.; All authors have read and agreed to the published version of the manuscript.

Funding: This research was funded by Austrian Science Fund FWF (DK-SPIN W1206 to MK).

Acknowledgments: The authors thank P. Jennings and G. Gstraunthaler, as well as the StemBANCC consortium for providing the iPSC line. The authors report no conflict of interest. Open Access Funding by the Austrian Science Fund (FWF).

Conflicts of Interest: The authors declare that there is no conflict of interest.

\section{References}

1. Rostock, C.; Schrenk-Siemens, K.; Pohle, J.; Siemens, J. Human vs. Mouse Nociceptors-Similarities and Differences. Neuroscience 2018, 387, 13-27. [CrossRef]

2. Schwaid, A.G.; Krasowka-Zoladek, A.; Chi, A.; Cornella-Taracido, I. Comparison of the Rat and Human Dorsal Root Ganglion Proteome. Sci. Rep. 2018, 8, 13469. [CrossRef] [PubMed]

3. Chang, E.A.; Jin, S.W.; Nam, M.H.; Kim, S.D. Human Induced Pluripotent Stem Cells: Clinical Significance and Applications in Neurologic Diseases. J. Korean Neurosurg. Soc. 2019, 62, 493-501. [CrossRef] [PubMed]

4. Chambers, S.M.; Qi, Y.; Mica, Y.; Lee, G.; Zhang, X.J.; Niu, L.; Bilsland, J.; Cao, L.; Stevens, E.; Whiting, P.; et al. Combined small-molecule inhibition accelerates developmental timing and converts human pluripotent stem cells into nociceptors. Nat. Biotechnol. 2012, 30, 715-720. [CrossRef] [PubMed]

5. Eberhardt, E.; Havlicek, S.; Schmidt, D.; Link, A.S.; Neacsu, C.; Kohl, Z.; Hampl, M.; Kist, A.M.; Klinger, A.; Nau, C.; et al. Pattern of Functional TTX-Resistant Sodium Channels Reveals a Developmental Stage of Human iPSC- and ESC-Derived Nociceptors. Stem Cell Rep. 2015, 5, 305-313. [CrossRef] 
6. Nahorski, M.S.; Al-Gazali, L.; Hertecant, J.; Owen, D.J.; Borner, G.H.; Chen, Y.C.; Benn, C.L.; Carvalho, O.P.; Shaikh, S.S.; Phelan, A.; et al. A novel disorder reveals clathrin heavy chain-22 is essential for human pain and touch development. Brain 2015, 138, 2147-2160. [CrossRef]

7. Namer, B.; Schmidt, D.; Eberhardt, E.; Maroni, M.; Dorfmeister, E.; Kleggetveit, I.P.; Kaluza, L.; Meents, J.; Gerlach, A.; Lin, Z.; et al. Pain relief in a neuropathy patient by lacosamide: Proof of principle of clinical translation from patient-specific iPS cell-derived nociceptors. EBioMedicine 2019, 39, 401-408. [CrossRef]

8. Meents, J.E.; Bressan, E.; Sontag, S.; Foerster, A.; Hautvast, P.; Rosseler, C.; Hampl, M.; Schuler, H.; Goetzke, R.; Le, T.K.C.; et al. The role of Nav1.7 in human nociceptors: Insights from human induced pluripotent stem cell-derived sensory neurons of erythromelalgia patients. Pain 2019, 160, 1327-1341. [CrossRef]

9. McDermott, L.A.; Weir, G.A.; Themistocleous, A.C.; Segerdahl, A.R.; Blesneac, I.; Baskozos, G.; Clark, A.J.; Millar, V.; Peck, L.J.; Ebner, D.; et al. Defining the Functional Role of NaV1.7 in Human Nociception. Neuron 2019, 101, 905-919. [CrossRef]

10. Pettingill, P.; Weir, G.A.; Wei, T.; Wu, Y.; Flower, G.; Lalic, T.; Handel, A.; Duggal, G.; Chintawar, S.; Cheung, J.; et al. A causal role for TRESK loss of function in migraine mechanisms. Brain 2019, 142, 3852-3867. [CrossRef]

11. Chen, Y.C.; Auer-Grumbach, M.; Matsukawa, S.; Zitzelsberger, M.; Themistocleous, A.C.; Strom, T.M.; Samara, C.; Moore, A.W.; Cho, L.T.; Young, G.T.; et al. Transcriptional regulator PRDM12 is essential for human pain perception. Nat. Genet. 2015, 47, 803-808. [CrossRef] [PubMed]

12. Cao, L.; McDonnell, A.; Nitzsche, A.; Alexandrou, A.; Saintot, P.P.; Loucif, A.J.; Brown, A.R.; Young, G.; Mis, M.; Randall, A.; et al. Pharmacological reversal of a pain phenotype in iPSC-derived sensory neurons and patients with inherited erythromelalgia. Sci. Transl. Med. 2016, 8, 335ra356. [CrossRef] [PubMed]

13. Wainger, B.J.; Buttermore, E.D.; Oliveira, J.T.; Mellin, C.; Lee, S.; Saber, W.A.; Wang, A.J.; Ichida, J.K.; Chiu, I.M.; Barrett, L.; et al. Modeling pain in vitro using nociceptor neurons reprogrammed from fibroblasts. Nat. Neurosci. 2015, 18, 17-24. [CrossRef] [PubMed]

14. Emery, E.C.; Young, G.T.; Berrocoso, E.M.; Chen, L.; McNaughton, P.A. HCN2 ion channels play a central role in inflammatory and neuropathic pain. Science 2011, 333, 1462-1466. [CrossRef]

15. Ricoy, U.M.; Frerking, M.E. Distinct roles for Cav2.1-2.3 in activity-dependent synaptic dynamics. J. Neurophysiol. 2014, 111, 2404-2413. [CrossRef]

16. Mochida, S. Presynaptic calcium channels. Neurosci. Res. 2018, 127, 33-44. [CrossRef]

17. Mochida, S. Presynaptic Calcium Channels. Int. J. Mol. Sci. 2019, 20, 2217. [CrossRef]

18. Chen, J.T.; Guo, D.; Campanelli, D.; Frattini, F.; Mayer, F.; Zhou, L.; Kuner, R.; Heppenstall, P.A.; Knipper, M.; $\mathrm{Hu}$, J. Presynaptic GABAergic inhibition regulated by BDNF contributes to neuropathic pain induction. Nat. Commun. 2014, 5, 5331. [CrossRef]

19. Morrison, M.; Klein, C.; Clemann, N.; Collier, D.A.; Hardy, J.; Heisserer, B.; Cader, M.Z.; Graf, M.; Kaye, J. StemBANCC: Governing Access to Material and Data in a Large Stem Cell Research Consortium. Stem Cell Rev. Rep. 2015, 11, 681-687. [CrossRef]

20. Quarta, S.; Mitric, M.; Kalpachidou, T.; Mair, N.; Schiefermeier-Mach, N.; Andratsch, M.; Qi, Y.; Langeslag, M.; Malsch, P.; Rose-John, S.; et al. Impaired mechanical, heat, and cold nociception in a murine model of genetic TACE/ADAM17 knockdown. FASEB J. 2019, 33, 4418-4431. [CrossRef]

21. Geisler, S.; Schopf, C.L.; Stanika, R.; Kalb, M.; Campiglio, M.; Repetto, D.; Traxler, L.; Missler, M.; Obermair, G.J Presynaptic alpha2delta-2 Calcium Channel Subunits Regulate Postsynaptic GABAA Receptor Abundance and Axonal Wiring. J. Neurosci. 2019, 39, 2581-2605. [CrossRef] [PubMed]

22. Ghinia, M.G.; Novelli, E.; Sajgo, S.; Badea, T.C.; Strettoi, E. Brn3a and Brn3b knockout mice display unvaried retinal fine structure despite major morphological and numerical alterations of ganglion cells. J. Comp. Neurol. 2019, 527, 187-211. [CrossRef] [PubMed]

23. Khattar, P.; Friedrich, F.W.; Bonne, G.; Carrier, L.; Eschenhagen, T.; Evans, S.M.; Schwartz, K.; Fiszman, M.Y.; Vilquin, J.T. Distinction between two populations of islet-1-positive cells in hearts of different murine strains. Stem Cells Dev. 2011, 20, 1043-1052. [CrossRef] [PubMed]

24. Lenkey, N.; Kirizs, T.; Holderith, N.; Mate, Z.; Szabo, G.; Vizi, E.S.; Hajos, N.; Nusser, Z. Tonic endocannabinoid-mediated modulation of GABA release is independent of the CB1 content of axon terminals. Nat. Commun. 2015, 6, 6557. [CrossRef] [PubMed]

25. Parajuli, L.K.; Nakajima, C.; Kulik, A.; Matsui, K.; Schneider, T.; Shigemoto, R.; Fukazawa, Y. Quantitative regional and ultrastructural localization of the $\mathrm{Ca}(\mathrm{v}) 2.3$ subunit of R-type calcium channel in mouse brain. J. Neurosci. 2012, 32, 13555-13567. [CrossRef] [PubMed] 
26. Miyamoto, C.; Kojo, S.; Yamashita, M.; Moro, K.; Lacaud, G.; Shiroguchi, K.; Taniuchi, I.; Ebihara, T. Runx/Cbfbeta complexes protect group 2 innate lymphoid cells from exhausted-like hyporesponsiveness during allergic airway inflammation. Nat. Commun. 2019, 10, 447. [CrossRef]

27. Liu, Z.; Cao, Y.; Liu, G.; Yin, S.; Ma, J.; Liu, J.; Zhang, M.; Wang, Y. p75 neurotrophin receptor regulates NGF-induced myofibroblast differentiation and collagen synthesis through MRTF-A. Exp. Cell Res. 2019, 383, 111504. [CrossRef]

28. Ono, K.; Ye, Y.; Viet, C.T.; Dang, D.; Schmidt, B.L. TRPV1 expression level in isolectin B(4)-positive neurons contributes to mouse strain difference in cutaneous thermal nociceptive sensitivity. J. Neurophysiol. 2015, 113, 3345-3355. [CrossRef]

29. Quarta, S.; Baeumer, B.E.; Scherbakov, N.; Andratsch, M.; Rose-John, S.; Dechant, G.; Bandtlow, C.E.; Kress, M. Peripheral nerve regeneration and NGF-dependent neurite outgrowth of adult sensory neurons converge on STAT3 phosphorylation downstream of neuropoietic cytokine receptor gp130. J. Neurosci. 2014, 34, 13222-13233. [CrossRef]

30. Hughes, D.I.; Sikander, S.; Kinnon, C.M.; Boyle, K.A.; Watanabe, M.; Callister, R.J.; Graham, B.A. Morphological, neurochemical and electrophysiological features of parvalbumin-expressing cells: A likely source of axo-axonic inputs in the mouse spinal dorsal horn. J. Physiol. 2012, 590, 3927-3951. [CrossRef]

31. Camprubi-Robles, M.; Mair, N.; Andratsch, M.; Benetti, C.; Beroukas, D.; Rukwied, R.; Langeslag, M.; Proia, R.L.; Schmelz, M.; Ferrer Montiel, A.V.; et al. Sphingosine-1-phosphate-induced nociceptor excitation and ongoing pain behavior in mice and humans is largely mediated by S1P3 receptor. J. Neurosci. 2013, 33, 2582-2592. [CrossRef] [PubMed]

32. Dykes, I.M.; Tempest, L.; Lee, S.I.; Turner, E.E. Brn3a and Islet1 act epistatically to regulate the gene expression program of sensory differentiation. J. Neurosci. 2011, 31, 9789-9799. [CrossRef] [PubMed]

33. Chuang, J.H.; Yarmishyn, A.A.; Hwang, D.K.; Hsu, C.C.; Wang, M.L.; Yang, Y.P.; Chien, K.H.; Chiou, S.H.; Peng, C.H.; Chen, S.J. Expression profiling of cell-intrinsic regulators in the process of differentiation of human iPSCs into retinal lineages. Stem Cell Res. Ther. 2018, 9, 140. [CrossRef] [PubMed]

34. Chen, C.L.; Broom, D.C.; Liu, Y.; de Nooij, J.C.; Li, Z.; Cen, C.; Samad, O.A.; Jessell, T.M.; Woolf, C.J.; Ma, Q. Runx1 determines nociceptive sensory neuron phenotype and is required for thermal and neuropathic pain. Neuron 2006, 49, 365-377. [CrossRef]

35. Wang, J.W.; Stifani, S. Roles of Runx Genes in Nervous System Development. Adv. Exp. Med. Biol. 2017, 962, 103-116. [CrossRef]

36. Marmigere, F.; Montelius, A.; Wegner, M.; Groner, Y.; Reichardt, L.F.; Ernfors, P. The Runx1/AML1 transcription factor selectively regulates development and survival of TrkA nociceptive sensory neurons. Nat. Neurosci. 2006, 9, 180-187. [CrossRef]

37. Lopes, C.; Liu, Z.; Xu, Y.; Ma, Q. Tlx3 and Runx1 act in combination to coordinate the development of a cohort of nociceptors, thermoceptors, and pruriceptors. J. Neurosci. 2012, 32, 9706-9715. [CrossRef]

38. Lou, S.; Pan, X.; Huang, T.; Duan, B.; Yang, F.C.; Yang, J.; Xiong, M.; Liu, Y.; Ma, Q. Incoherent feed-forward regulatory loops control segregation of C-mechanoreceptors, nociceptors, and pruriceptors. J. Neurosci. 2015, 35, 5317-5329. [CrossRef]

39. Obata, K.; Katsura, H.; Sakurai, J.; Kobayashi, K.; Yamanaka, H.; Dai, Y.; Fukuoka, T.; Noguchi, K. Suppression of the p75 neurotrophin receptor in uninjured sensory neurons reduces neuropathic pain after nerve injury. J. Neurosci. 2006, 26, 11974-11986. [CrossRef]

40. O’Leary, V.B.; O'Connell, M.; Antyborzec, I.; Ntziachristos, V.; Oliver Dolly, J.; Ovsepian, S.V. Alleviation of Trigeminal Nociception Using p75 Neurotrophin Receptor Targeted Lentiviral Interference Therapy. Neurotherapeutics 2018, 15, 489-499. [CrossRef]

41. Nocchi, L.; Portulano, C.; Franciosa, F.; Doleschall, B.; Panea, M.; Roy, N.; Maffei, M.; Gargano, A.; Perlas, E.; Heppenstall, P.A. Nerve growth factor-mediated photoablation of nociceptors reduces pain behavior in mice. Pain 2019, 160, 2305-2315. [CrossRef]

42. Chen, Z.; Donnelly, C.R.; Dominguez, B.; Harada, Y.; Lin, W.; Halim, A.S.; Bengoechea, T.G.; Pierchala, B.A.; Lee, K.F. p75 Is Required for the Establishment of Postnatal Sensory Neuron Diversity by Potentiating Ret Signaling. Cell Rep. 2017, 21, 707-720. [CrossRef] [PubMed]

43. Sousa-Valente, J.; Andreou, A.P.; Urban, L.; Nagy, I. Transient receptor potential ion channels in primary sensory neurons as targets for novel analgesics. Br. J. Pharmacol. 2014, 171, 2508-2527. [CrossRef] [PubMed] 
44. Lee, H.; Dean, C.; Isacoff, E. Alternative splicing of neuroligin regulates the rate of presynaptic differentiation. J. Neurosci. 2010, 30, 11435-11446. [CrossRef] [PubMed]

45. Ramirez, D.; Zuniga, R.; Concha, G.; Zuniga, L. HCN Channels: New Therapeutic Targets for Pain Treatment. Molecules 2018, 23, 2094. [CrossRef] [PubMed]

46. Israel, M.R.; Tanaka, B.S.; Castro, J.; Thongyoo, P.; Robinson, S.D.; Zhao, P.; Deuis, J.R.; Craik, D.J.; Durek, T.; Brierley, S.M.; et al. NaV 1.6 regulates excitability of mechanosensitive sensory neurons. J. Physiol. 2019, 597, 3751-3768. [CrossRef]

47. Erickson, A.; Deiteren, A.; Harrington, A.M.; Garcia-Caraballo, S.; Castro, J.; Caldwell, A.; Grundy, L.; Brierley, S.M. Voltage-gated sodium channels: (NaV)igating the field to determine their contribution to visceral nociception. J. Physiol. 2018, 596, 785-807. [CrossRef]

48. Eijkelkamp, N.; Linley, J.E.; Baker, M.D.; Minett, M.S.; Cregg, R.; Werdehausen, R.; Rugiero, F.; Wood, J.N. Neurological perspectives on voltage-gated sodium channels. Brain 2012, 135, 2585-2612. [CrossRef]

49. Mis, M.A.; Yang, Y.; Tanaka, B.S.; Gomis-Perez, C.; Liu, S.; Dib-Hajj, F.; Adi, T.; Garcia-Milian, R.; Schulman, B.R.; Dib-Hajj, S.D.; et al. Resilience to Pain: A Peripheral Component Identified Using Induced Pluripotent Stem Cells and Dynamic Clamp. J. Neurosci. 2019, 39, 382-392. [CrossRef]

50. Bourinet, E.; Altier, C.; Hildebrand, M.E.; Trang, T.; Salter, M.W.; Zamponi, G.W. Calcium-permeable ion channels in pain signaling. Physiol. Rev. 2014, 94, 81-140. [CrossRef]

51. Wilke, B.U.; Kummer, K.K.; Leitner, M.G.; Kress, M. Chloride-The Underrated Ion in Nociceptors. Front. Neurosci. 2020, 14, 287. [CrossRef] [PubMed]

52. Price, T.J.; Cervero, F.; Gold, M.S.; Hammond, D.L.; Prescott, S.A. Chloride regulation in the pain pathway. Brain Res. Rev. 2009, 60, 149-170. [CrossRef] [PubMed]

53. Mogil, J.S. Animal models of pain: Progress and challenges. Nat. Rev. Neurosci. 2009, 10, 283-294. [CrossRef] [PubMed]

54. Burma, N.E.; Leduc-Pessah, H.; Fan, C.Y.; Trang, T. Animal models of chronic pain: Advances and challenges for clinical translation. J. Neurosci. Res. 2017, 95, 1242-1256. [CrossRef] [PubMed]

55. Chambers, S.M.; Fasano, C.A.; Papapetrou, E.P.; Tomishima, M.; Sadelain, M.; Studer, L. Highly efficient neural conversion of human ES and iPS cells by dual inhibition of SMAD signaling. Nat. Biotechnol. 2009, 27, 275-280. [CrossRef] [PubMed]

56. Schwartzentruber, J.; Foskolou, S.; Kilpinen, H.; Rodrigues, J.; Alasoo, K.; Knights, A.J.; Patel, M.; Goncalves, A.; Ferreira, R.; Benn, C.L.; et al. Molecular and functional variation in iPSC-derived sensory neurons. Nat. Genet. 2018, 50, 54-61. [CrossRef]

57. Volpato, V.; Smith, J.; Sandor, C.; Ried, J.S.; Baud, A.; Handel, A.; Newey, S.E.; Wessely, F.; Attar, M.; Whiteley, E.; et al. Reproducibility of Molecular Phenotypes after Long-Term Differentiation to Human iPSC-Derived Neurons: A Multi-Site Omics Study. Stem Cell Rep. 2018, 11, 897-911. [CrossRef]

58. Schrenk-Siemens, K.; Rosseler, C.; Lampert, A. Translational Model Systems for Complex Sodium Channel Pathophysiology in Pain. Handb. Exp. Pharmacol. 2018, 246, 355-369. [CrossRef]

59. Alsaloum, M.; Estacion, M.; Almomani, R.; Gerrits, M.M.; Bonhof, G.J.; Ziegler, D.; Malik, R.; Ferdousi, M.; Lauria, G.; Merkies, I.S.; et al. A gain-of-function sodium channel beta2-subunit mutation in painful diabetic neuropathy. Mol. Pain 2019, 15, 1744806919849802. [CrossRef]

60. Klein, T.; Klug, K.; Henkel, L.; Kwok, C.K.; Edenhofer, F.; Klopocki, E.; Kurth, I.; Uceyler, N. Generation of two induced pluripotent stem cell lines from skin fibroblasts of sisters carrying a c.1094C $>$ A variation in the SCN10A gene potentially associated with small fiber neuropathy. Stem Cell Res. 2019, 35, 101396. [CrossRef]

61. Nebe, J.; Vanegas, H.; Neugebauer, V.; Schaible, H.G. Omega-agatoxin IVA, a P-type calcium channel antagonist, reduces nociceptive processing in spinal cord neurons with input from the inflamed but not from the normal knee joint-an electrophysiological study in the rat in vivo. Eur. J. Neurosci. 1997, 9, 2193-2201. [CrossRef] [PubMed]

62. Diaz, A.; Dickenson, A.H. Blockade of spinal N- and P-type, but not L-type, calcium channels inhibits the excitability of rat dorsal horn neurones produced by subcutaneous formalin inflammation. Pain 1997, 69, 93-100. [CrossRef]

63. Matthews, E.A.; Bee, L.A.; Stephens, G.J.; Dickenson, A.H. The Cav2.3 calcium channel antagonist SNX-482 reduces dorsal horn neuronal responses in a rat model of chronic neuropathic pain. Eur. J. Neurosci. 2007, 25, 3561-3569. [CrossRef] [PubMed] 
64. Geisler, S.; Schopf, C.L.; Obermair, G.J. Emerging evidence for specific neuronal functions of auxiliary calcium channel alpha(2)delta subunits. Gen. Physiol. Biophys. 2015, 34, 105-118. [CrossRef]

65. Skubatz, H. Neuropeptide FF (FLFQPQRF-NH2) and its Fragments Bind to alpha2delta Subunit of Voltage-Gated Calcium Channels. J. Pharm. Pharm. Sci. 2019, 22, 292-300. [CrossRef]

66. Field, M.J.; Cox, P.J.; Stott, E.; Melrose, H.; Offord, J.; Su, T.Z.; Bramwell, S.; Corradini, L.; England, S.; Winks, J.; et al. Identification of the alpha2-delta-1 subunit of voltage-dependent calcium channels as a molecular target for pain mediating the analgesic actions of pregabalin. Proc. Natl. Acad. Sci. USA 2006, 103, 17537-17542. [CrossRef]

67. Sondermann, J.R.; Barry, A.M.; Jahn, O.; Michel, N.; Abdelaziz, R.; Kugler, S.; Gomez-Varela, D.; Schmidt, M. Vti1b promotes TRPV1 sensitization during inflammatory pain. Pain 2019, 160, 508-527. [CrossRef]

68. Meng, J.; Wang, J.; Steinhoff, M.; Dolly, J.O. TNFalpha induces co-trafficking of TRPV1/TRPA1 in VAMP1-containing vesicles to the plasmalemma via Munc18-1/syntaxin1/SNAP-25 mediated fusion. Sci. Rep. 2016, 6, 21226. [CrossRef]

69. Goswami, C.; Rademacher, N.; Smalla, K.H.; Kalscheuer, V.; Ropers, H.H.; Gundelfinger, E.D.; Hucho, T. TRPV1 acts as a synaptic protein and regulates vesicle recycling. J. Cell Sci. 2010, 123, 2045-2057. [CrossRef]

70. Raingo, J.; Castiglioni, A.J.; Lipscombe, D. Alternative splicing controls G protein-dependent inhibition of N-type calcium channels in nociceptors. Nat. Neurosci. 2007, 10, 285-292. [CrossRef]

71. Kouranova, E.V.; Strassle, B.W.; Ring, R.H.; Bowlby, M.R.; Vasilyev, D.V. Hyperpolarization-activated cyclic nucleotide-gated channel mRNA and protein expression in large versus small diameter dorsal root ganglion neurons: Correlation with hyperpolarization-activated current gating. Neuroscience 2008, 153, 1008-1019. [CrossRef] [PubMed]

72. Acosta, C.; McMullan, S.; Djouhri, L.; Gao, L.; Watkins, R.; Berry, C.; Dempsey, K.; Lawson, S.N. HCN1 and HCN2 in Rat DRG neurons: Levels in nociceptors and non-nociceptors, NT3-dependence and influence of CFA-induced skin inflammation on HCN2 and NT3 expression. PLoS ONE 2012, 7, e50442. [CrossRef] [PubMed]

73. Lainez, S.; Tsantoulas, C.; Biel, M.; McNaughton, P.A. HCN3 ion channels: Roles in sensory neuronal excitability and pain. J. Physiol. 2019, 597, 4661-4675. [CrossRef] [PubMed]

74. Liu, X.; Zhang, L.; Jin, L.; Tan, Y.; Li, W.; Tang, J. HCN2 contributes to oxaliplatin-induced neuropathic pain through activation of the CaMKII/CREB cascade in spinal neurons. Mol. Pain 2018, 14, 1744806918778490. [CrossRef] [PubMed]

75. Djouhri, L.; Smith, T.; Ahmeda, A.; Alotaibi, M.; Weng, X. Hyperpolarization-activated cyclic nucleotide-gated channels contribute to spontaneous activity in L4 C-fiber nociceptors, but not Abeta-non-nociceptors, after axotomy of L5-spinal nerve in the rat in vivo. Pain 2018, 159, 1392-1402. [CrossRef] [PubMed]

76. Smith, T.; Al Otaibi, M.; Sathish, J.; Djouhri, L. Increased expression of HCN2 channel protein in L4 dorsal root ganglion neurons following axotomy of L5- and inflammation of L4-spinal nerves in rats. Neuroscience 2015, 295, 90-102. [CrossRef]

77. Young, G.T.; Emery, E.C.; Mooney, E.R.; Tsantoulas, C.; McNaughton, P.A. Inflammatory and neuropathic pain are rapidly suppressed by peripheral block of hyperpolarisation-activated cyclic nucleotide-gated ion channels. Pain 2014, 155, 1708-1719. [CrossRef]

78. Emery, E.C.; Young, G.T.; McNaughton, P.A. HCN2 ion channels: An emerging role as the pacemakers of pain. Trends Pharmacol. Sci. 2012, 33, 456-463. [CrossRef]

79. Jiang, Y.Q.; Xing, G.G.; Wang, S.L.; Tu, H.Y.; Chi, Y.N.; Li, J.; Liu, F.Y.; Han, J.S.; Wan, Y. Axonal accumulation of hyperpolarization-activated cyclic nucleotide-gated cation channels contributes to mechanical allodynia after peripheral nerve injury in rat. Pain 2008, 137, 495-506. [CrossRef]

80. Chaplan, S.R.; Guo, H.Q.; Lee, D.H.; Luo, L.; Liu, C.; Kuei, C.; Velumian, A.A.; Butler, M.P.; Brown, S.M.; Dubin, A.E. Neuronal hyperpolarization-activated pacemaker channels drive neuropathic pain. J. Neurosci. 2003, 23, 1169-1178. [CrossRef]

81. Schnorr, S.; Eberhardt, M.; Kistner, K.; Rajab, H.; Kasser, J.; Hess, A.; Reeh, P.; Ludwig, A.; Herrmann, S. HCN2 channels account for mechanical (but not heat) hyperalgesia during long-standing inflammation. Pain 2014, 155, 1079-1090. [CrossRef] [PubMed]

82. Labrakakis, C.; Tong, C.K.; Weissman, T.; Torsney, C.; MacDermott, A.B. Localization and function of ATP and GABAA receptors expressed by nociceptors and other postnatal sensory neurons in rat. J. Physiol. 2003, 549, 131-142. [CrossRef] [PubMed] 
83. Ito, K.; Tanaka, K.; Nishibe, Y.; Hasegawa, J.; Ueno, H. GABA-synthesizing enzyme, GAD67, from dermal fibroblasts: Evidence for a new skin function. Biochim. Biophys. Acta 2007, 1770, 291-296. [CrossRef] [PubMed]

84. Ault, B.; Hildebrand, L.M. GABAA receptor-mediated excitation of nociceptive afferents in the rat isolated spinal cord-tail preparation. Neuropharmacology 1994, 33, 109-114. [CrossRef]

85. Zimmerman, A.L.; Kovatsis, E.M.; Pozsgai, R.Y.; Tasnim, A.; Zhang, Q.; Ginty, D.D. Distinct Modes of Presynaptic Inhibition of Cutaneous Afferents and Their Functions in Behavior. Neuron 2019, 102, 420-434.e428. [CrossRef]

(C) 2020 by the authors. Licensee MDPI, Basel, Switzerland. This article is an open access article distributed under the terms and conditions of the Creative Commons Attribution (CC BY) license (http://creativecommons.org/licenses/by/4.0/). 